Instituto Internacional de Investigación y Desarrollo Tecnológico Educativo INDTEC, C.A.

DOI: https://doi.org/10.29394/Scientific.issn.2542-2987.2020.5.18.19.358-370

OAI-PMH: http://www.indteca.com/ojs/index.php/Revista Scientific/oai

Ensayo Original / Original Essay

\title{
Dimensión cultural de la educación: Aproximación a teorías clásicas pensadas a la luz de nuestros días
}

\author{
Autora: Mireya Yolanda Arias Palomeque \\ Universidad Nacional de Educación, UNAE \\ mireya.arias@unae.edu.ec \\ Azogues, Ecuador \\ https://orcid.org/0000-0002-7258-7619
}

\section{Resumen}

El presente ensayo consiste en una reflexión sobre las circunstancias culturales actuales en las que la educación tiene lugar. El propósito es comprender a las prácticas educativas como un componente más de la dimensión cultural de la vida humana $\mathrm{y}$, por tanto, atravesada por características de ésta (modernidad, racismo, homogenización). Para esto, hemos repasado a autores clásicos de la vertiente de la Teoría Crítica de la Cultura, tales como Echeverría (2001); Nietzsche (1996); Freud (1992); Adorno y Horkheimer (1998); Quijano (2000); y Castro (2014) y analizamos la vigencia de sus textos. Los principales tópicos a abordarse son: la cultura como esfera imprescindible de la vida humana, las razones que justifican su existencia y ciertas particularidades de esta cultura moderna como las industrias culturales, homogenización y racismo. La conclusión de esta reflexión es que el papel de la educación es, ahora y como siempre, fundamental en la consigna de esbozar una dimensión cultural que genere prácticas y representaciones más justas e igualitarias.

Palabras clave: cultura; educación; sociología de la educación; diversidad cultural.

\section{Cómo citar este ensayo:}

Arias, M. (2020). Dimensión cultural de la educación: Aproximación a teorías clásicas pensadas a la luz de nuestros días. Revista Scientific, 5(18), 358-370, e-ISSN: 2542-2987. Recuperado de: https://doi.org/10.29394/Scientific.issn.2542-2987.2020.5.18.19.358-370

Fecha de Recepción: 25-06-2020
Fecha de Aceptación: 18-09-2020
Fecha de Publicación: 05-11-2020 
Instituto Internacional de Investigación y Desarrollo Tecnológico Educativo INDTEC, C.A.

DOI: https://doi.org/10.29394/Scientific.issn.2542-2987.2020.5.18.19.358-370

OAI-PMH: http://www.indteca.com/ojs/index.php/Revista_Scientific/oai

Ensayo Original / Original Essay

\title{
Cultural dimension of education: An approach to classical theories thought in the light of our days
}

\begin{abstract}
This essay consists of a reflection on the current cultural circumstances in which education takes place. The purpose is to understand educational practices as one more component of the cultural dimension of human life and, therefore, crossed by its characteristics (modernity, racism, homogenization). For this, we have reviewed classical authors from the Critical Theory of Culture, such as Echeverría (2001); Nietzsche (1996); Freud (1992); Adorno and Horkheimer (1998); Quijano (2000); and Castro (2014) and we analyze the validity of their texts. The main topics to be addressed are: culture as an essential sphere of human life, the reasons that justify its existence and certain particularities of this modern culture such as cultural industries, homogenization and racism. The conclusion of this reflection is that the role of education is, now and as always, fundamental in the slogan of outlining a cultural dimension that generates more just and egalitarian practices and representations.
\end{abstract}

Keywords: culture; education; educational sociology; cultural diversity.

\section{How to cite this essay:}

Arias, M. (2020). Cultural dimension of education: An approach to classical theories thought in the light of our days. Revista Scientific, 5(18), 358-370, e-ISSN: 2542-2987. Recovered from: https://doi.org/10.29394/Scientific.issn.2542-2987.2020.5.18.19.358-370

Date Received: 25-06-2020
Date Acceptance:

18-09-2020
Date Publication:

05-11-2020 


\section{Introducción}

Pretendamos un escenario hollywoodense: estamos parados tras un cristal y, a través de él, podemos observar el mundo. Cualquier plaza, calle o mercado e incluso las cocinas o los dormitorios de las casas, todos estos espacios son accesibles a nuestra mirada. ¿Qué veríamos entonces? acciones humanas naturales: caminar, hablar, comer, dormir, etc. Pero veríamos también cómo un hombre cede el asiento a una mujer, una madre da la bendición a sus hijos antes de dormir, una mesa es dispuesta con una serie de cubiertos calculados simétricamente... en fin, acciones humanas culturales.

¿Qué es la cultura entonces? En este ensayo plantearemos algunas reflexiones en torno a esta pregunta para poder situar a la educación en su contexto. Empezamos por definir a la cultura como un ámbito imprescindible de la vida social, de la mano de los planteamientos de Echeverría (2001a). Luego, reflexionamos sobre los motivos que justifican la existencia de la cultura, considerando la argumentación clásica y potente de Nietzsche (1996a), y contrastándola con el punto de vista de Freud (1992a), y finalmente, abordamos ciertas particularidades de la cultura "moderna", centrándonos principalmente en las industrias culturales, citando a Adorno y Horkheimer (1998a), y la homogenización de un estilo de vida con tintes clasistas y racistas, como lo proponen Quijano (2000a), y Castro (2014a).

\section{Desarrollo}

\subsection{La cultura como una dimensión indispensable de la vida humana}

Para empezar, siguiendo el argumento de Echeverría (2001b): afirmamos que la cultura, como dimensión de la vida social, es inevitable. Es decir, pese a que gran parte de los actos humanos tengan una finalidad $o$ funcionalidad definidas, hay una serie de acciones cotidianas que no pueden entenderse desde su utilidad pragmática, sino desde su dimensión cultural. De 
hecho, muchos de los actos humanos están precedidos por otros actos que les resultan imprescindibles en la configuración del sentido.

Al hablar de utilidad, funcionalidad o finalidad de las acciones humanas, nos referimos a que éstas estén regidas por una razón instrumental sentada sobre la lógica convencional. Pongamos dos ejemplos: comemos porque de eso depende nuestra supervivencia y construimos casas porque queremos resguardarnos de la naturaleza. Pero, por qué hay varios rituales frente a una mesa servida o por qué se habla de diseño de interiores y feng shui y no solo de arquitectura. Las respuestas evidencian la existencia de esta dimensión cultural de la vida social, como la denominó Echeverría (2001c): y dejan ver, por consiguiente, que todos estamos imbuidos, de una u otra manera, en ella o, dicho de otra forma, que el hombre no es capaz de ser únicamente funcional, sino también cultural.

En este sentido, vemos que la cultura moldea cómo nos entendemos y cómo entendemos al resto. Entendemos el sentido de nuestras acciones y las calificamos como racionales. Aparece entonces lo irracional, lo disfuncional o sin sentido en contraposición a lo que nosotros hemos codificado previamente. Es decir, hay un concepto de racionalidad que crea lo irracional, pero lo curioso es que siempre se traslada la disfuncionalidad a un grupo humano o individuo diferente.

Vemos que la existencia de la cultura, como dimensión que acompaña nuestra vida cotidiana, no solamente actúa como una banda sonora inofensiva, sino que puede ser el caldo de cultivo de grandes enfrentamientos. Los innumerables conflictos políticos y religiosos que se dan en el mundo día a día, los enfrentamientos entre partidarios de distintos equipos de fútbol o la vehemencia con la que se defiende a ciertas manifestaciones artísticas, son muestras claras de la existencia y la potencialidad de la cultura. 


\subsection{La cultura existe, pero ¿por qué?...}

En suma, diríamos que el ser humano necesita justificar sus acciones y para eso usa la cultura. Para profundizar en esta idea podemos citar el argumento de Nietzsche (1996b): en su Genealogía de la moral, donde el filósofo aborda el ascetismo como ideal de varios grupos de personas. El ascetismo es entendido como la renuncia a los placeres materiales para alcanzar la plenitud moral y espiritual, es decir, se considera que las acciones humanas (como comer, el sexo, gozar del lujo, etc.) son impuras.

En este sentido, Nietzsche (1996c): se pregunta por el significado de los ideales ascéticos para distintas personas y considera que, como el ascetismo implica renunciar a algo para conseguir un objetivo, para la filosofía este objetivo sería la verdad y para la religión, Dios. Es decir, los ideales ascéticos para los filósofos son lo que les permite ser independientes. Por su parte, los sacerdotes encarnan los ideales ascéticos pues ellos los crearon para legitimar su dominación y su presencia.

Pero ¿por qué la gente común considera el ascetismo como algo deseable?, ¿por qué deberíamos renunciar a lo que nos da felicidad en este mundo?, ¿por qué queremos imitar y agradar a las personas que encarnan estos ideales?. Conforme a Nietzsche (1996d), el sentido común no es suficiente para entender los ideales ascéticos, pues:

Ese odio contra lo humano, más aún, contra lo animal, más aún, contra lo material, esa repugnancia ante los sentidos, ante la razón misma, el miedo a la felicidad y a la belleza, ese anhelo de apartarse de toda apariencia, cambio, devenir, muerte, deseo, anhelo mismo. Todo eso significa, atrevámonos a comprenderlo, una voluntad de la nada, una aversión contra la vida... (pág. 205).

La razón por la que la humanidad acepta los ideales ascéticos está en su horror al vacío. Las personas tememos profundamente a que la vida no tenga sentido, a que nuestras acciones no persigan un objetivo trascendental, 
a que el dolor y el sufrimiento no sean el pasaporte a una felicidad ulterior, y por este miedo, aceptamos los ideales ascéticos como sinónimo de sentido, verdad o dios. Así concluye Nietzsche (1996e), que:

En el hecho de que el ideal ascético haya significado tantas cosas para el hombre se expresa la realidad fundamental de la voluntad humana, su horror vacui (horror al vacío): esa voluntad necesita una meta -y prefiere querer la nada a no querer (pág. 128).

Vemos entonces que, para Nietzsche (1996f): la cultura (y sus ideales) dan sentido a la vida humana. Por el contrario, para Freud (1992b): la cultura representa un malestar para el hombre pues la dicha se entiende como la satisfacción del deseo o impulso corporal y la cultura le impide manifestarse según sus deseos biológicos. También considera que la desdicha tiene varias fuentes: la sociedad y las reglas de la cultura, el cuerpo propio (porque es el origen de los deseos y va a arruinarse) y la naturaleza, porque genera trabajo y preocupación. Entonces, aparece la cultura generando este malestar porque nos protege de la naturaleza, nos distancia de los animales, pero nos niega la felicidad.

Con este argumento, además, entendemos a la cultura como un ente de regulación de vínculos recíprocos entre los hombres. Por ejemplo, el derecho, como parte de la cultura, surge para prevenir que los hombres se lastimen o irrespeten la propiedad privada. La moral aparece como ordenación de los impulsos naturales. En suma, la cultura no solo da sentido a la vida humana, sino que la regula constantemente.

\subsection{Particularidades de la cultura "moderna"}

Ahora bien, esta dimensión cultural que da sentido y regula la vida humana, actualmente tiene características particulares. En esta instancia es indispensable citar a Adorno y Horkheimer (1998b): y hablar de Industrias 
Culturales. Situando a la cultura en su contexto socio económico capitalista, consumista y de emergencia de lógicas neoliberales, la cultura no puede entenderse sino como una industria que existe para sostener y legitimar este modo de producción. Acorde con esto, Adorno y Horkheimer (1998c), manifiestan que:

Toda cultura de masas bajo el monopolio es idéntica, y su esqueleto -el armazón conceptual fabricado por aquélcomienza a dibujarse [...]. El cine y la radio no necesitan ya darse como arte. La verdad de que no son sino negocio les sirve de ideología que debe legitimar la porquería que producen deliberadamente (pág. 166).

Así mismo, las industrias culturales unifican y homogenizan el sentido común. Los poderosos monopolios culturales tienen la capacidad de estar presente a través de las pantallas de todos los hogares del mundo. Es bastante similar lo que observamos aquí a lo que se está observando en otros puntos del planeta y, en este contexto, la diversidad cultural de la que tanto se habla actualmente, se va perdiendo. Por otra parte, Adorno y Horkheimer (1998d), dicen que: "la técnica de la industria cultural ha llevado sólo a la estandarización y producción en serie y ha sacrificado aquello por lo cual la lógica de la obra se diferenciaba de la lógica del sistema social" (pág. 166).

Pese a que los planteamientos de Adorno y Horkheimer (1998e): fueron expuestos hace varias décadas, hoy en día tienen absoluta vigencia. De hecho, las dimensiones del fenómeno de las industrias culturales mediadas por el desarrollo del internet son inconmensurables. Podemos hablar de prensa digital, radios online, plataformas de Streaming, redes sociales, etc., y enseguida sentimos que su poder y presencia es enorme y seguramente lo será más aún, con el paso del tiempo. Esta nueva dinámica de la vida social, potencializada por el desarrollo tecnológico, ha desencadenado en nuevas formas de pensar, sentir, ser e incluso nuevas "profesiones" (por ejemplo, los Influencers); pero pueden seguir definiéndose como industrias culturales. 
Pero ¿por qué damos espacio a esta omnipresencia de los productos culturales? La respuesta tal vez esté en nuestra biología, lo hacemos porque la diversión es adictiva (neurológicamente hablando). Entonces, todo el tiempo estamos rodeados de contenido que refleja su objetivo de legitimar el sistema y no nos molesta, sino que lo disfrutamos. A juzgar por Adorno y Horkheimer (1998f): "las masas tienen lo que desean y se aferran obstinadamente a la ideología mediante la cual se les esclaviza" (pág. 178).

Pero, además de las características industriales de la cultura, es preciso pensar en su configuración colonial que enmarca un fuerte racismo que aún pervive. Ante esto, Quijano (2000b): habla de una colonialidad del poder que se da entre Europa y América Latina:

La globalización en curso es, en primer término, la culminación de un proceso que comenzó con la constitución de América y la del capitalismo colonial/moderno y eurocentrado como un nuevo patrón de poder mundial. Uno de los ejes fundamentales de ese patrón de poder es la clasificación social de la población mundial sobre la idea de raza, una construcción mental que expresa la experiencia básica de la dominación colonial y que desde entonces permea las dimensiones más importantes del poder mundial, incluyendo su racionalidad específica, el eurocentrismo (pág. 201).

Es decir que, para que el nuevo orden mundial se haya articulado de la manera en que lo ha hecho, la idea de raza ha sido fundamental. Según Quijano (2000c): raza es una categoría mental de la modernidad que se originó durante la conquista española en América y que inicialmente aludía las diferencias fenotípicas entre europeos y nativos, pero que luego se estructuró sobre supuestas diferencias biológicas entre estos grupos.

En este orden de ideas, se critica también la pretensión europea de ser artífices exclusivos de la modernidad. El relato europeo, tras la conquista americana, de acuerdo con Quijano (2000d): se erige sobre la idea de ser la "culminación de una trayectoria civilizatoria desde un estado de naturaleza" 
(pág. 212); y los hace considerarse como lo nuevo y lo moderno de la humanidad $\mathrm{y}$, a su vez, considerar a los otros como lo atrasado o subdesarrollado, por consiguiente, especies inferiores. Esta pretensión no es exclusiva de los europeos, pues muchas otras civilizaciones en la historia de la humanidad se han pensado a sí mismas como portadoras del saber y el desarrollo. Lo que sí ha sido novedoso y exclusivo de Europa, es su capacidad de hacer este relato hegemónico a lo largo del mundo y conseguir así afianzar su dominación.

Ahora bien, retomando el debate sobre la idea de raza, es interesante comprender cómo opera esta categoría. Partimos del planteamiento clásico de Weber (2012a): acerca de que el capitalismo se nutre de la ética protestante, cuyos postulados religiosos exhortan a un trabajo duro y continuo y entienden a la prosperidad como una bendición de Dios. Este argumento se complejiza al afirmar que el ethos capitalista necesita una imagen material para visibilizarse y esta es, precisamente la imagen de personas blancas, asevera Echeverría (2010a): que "el rasgo identitario-civilizatorio que queremos entender por "blanquitud" se consolida, en la historia real, de manera casual o arbitraria sobre la base de la apariencia étnica de la población europea noroccidental, sobre el trasfondo de una blancura racial-cultural" (pág. 59).

Así, la identidad humana, dentro de una cultura moderno-capitalista, se marca de forma visible en las personas blancas o en todas las que actúen como tales. Es decir, primero los sujetos deben tener un alto grado de productividad en el trabajo que los constituya como exitosos y bendecidos, luego, es necesario también que su apariencia y su entorno (casa) sean pulcras y ordenadas, explica Echeverría (2010b), que incluso: "hasta la propiedad de su lenguaje, la positividad discreta de su actitud y su mirada y la mesura y compostura de sus gestos y movimientos" (pág. 62).

En este sentido, la blanquitud alude no solo a las características físicas sino a un conjunto de valores, creencias y comportamientos que deben 
interiorizarse para ser un sujeto moderno. La cultura actual, entonces, se constituye sobre un racismo velado que puede integrar a sujetos con colores de piel distintas, siempre y cuando se comporten "como blancos".

Los postulados de Weber (2012b); y Echeverría (2010c): tienen absoluta vigencia. Hoy en día, hay todo un estilo de vida enmarcado en el paradigma de lo moderno y de la blanquitud: un trabajo divertido (muchas veces relacionado con la publicidad o ventas), una alimentación fitness (con productos orgánicos o veganos), un lugar donde vivir (propio o alquilado) amoblado con las últimas tendencias del diseño, viajes y aventuras, sonrisas para las fotos de las redes sociales acompañadas de hashtags motivacionales, etc. Todo este estilo de vida está orquestado para mantenernos en la dinámica del consumo y la productividad. Incluso se nos exhorta a amar nuestro trabajo y disfrutar de la precariedad. Y claro, al pensar en el estereotipo que encarne lo que hemos descrito, seguramente la primera imagen es la de un hombre blanco.

Así, hemos analizado algunas particularidades de la cultura y vemos que su potencialidad es enorme, por lo que su abordaje debe ser necesariamente desde una perspectiva crítica. Como afirma Castro (2014b): "tales teorías pueden ser dividas en dos grandes grupos: aquellas que ven la cultura como una "facticidad natural", y aquellas que, por el contrario, consideran la cultura como un ámbito estructurado por la praxis" (pág. 29).

Entonces, si desde la teoría crítica se considera que las teorías son construcciones sociales, entendemos a la cultura como una lucha por el poder y el control de los significados. Debemos mirar bajo los estereotipos de la felicidad moderna (basada en el consumo) y analizar el mundo como una estructura en conflicto con los sujetos. Solamente un estado de alerta constante, es decir, una teoría crítica de la cultura, nos permitirá movilizarnos. 


\section{Conclusión}

Finalmente, debemos preguntarnos ¿qué papel tiene la educación en este contexto cultural? La respuesta es fuerte: la educación es, tal vez, el último recurso de resistencia que nos queda. Veremos que muchos de los argumentos críticos esbozados hasta aquí, pueden ser reconsiderados a través de las potencialidades que ofrece la educación.

$\mathrm{Si}$, como hemos dicho, la cultura nos ayuda a enmarcar nuestras acciones dentro de la racionalidad; debemos promover una educación plural que rompa con la tendencia de calificar como irracional o disfuncional a quienes piensen o actúen diferente. Para esto, el currículo debe construirse en el marco de la diversidad.

Por otra parte, vimos también como el miedo a que la vida no tenga sentido nos empuja a los seres humanos a buscar ideales extraterrenales. Esta búsqueda puede ser apoyada por la educación al convertirse en una puerta hacia la emancipación, liberación y superación de brechas e inequidades. La educación tiene posibilidades transformadoras y puede generar agencia en las personas para que cambien su realidad material y encuentren su trascendencia.

Así mismo, en situaciones cotidianas y muy del mundo, vimos cómo los seres humanos nos enredamos en espirales de consumo y diversión, pues estas actividades nos generan placer y el placer es adictivo. Aquí también la educación es la encargada de brindarnos herramientas para dilucidar lo necesario y lo superficial y generar hábitos saludables para nuestro cuerpo y nuestra mente.

En definitiva, no podemos pensar a la educación como un ámbito ajeno al contexto social y cultural en el que se desarrolla. Tampoco podemos situarla en un contexto local sobre el cual podemos tener cierto "control". Esto no tiene sentido. Hay que ubicar a la educación dentro de las coordenadas locales y globales, comprendiendo que todo lo que aquí ocurre tiene causas y 
consecuencias en otras latitudes. Hay que reivindicar el poder crítico y de movilización que tienen los sujetos participantes de los procesos de enseñanza y aprendizaje.

La aspiración, finalmente, es que dentro del aula de clase podamos comprender a la cultura como una construcción social que moldea y da sentido a nuestras interacciones; y fuera del aula, seamos capaces de deconstruir prácticas y representaciones que no constituyan la educación inclusiva y liberadora de la que tanto se habla.

\section{Referencias}

Adorno, T., \& Horkheimer, M. (1998a,b,c,d,e,f). La Industria Cultural. En T. Adorno, \& M. Horkheimer, Dialéctica de la llustración. Madrid, España: Editorial Trotta.

Castro, S. (2014a,b). Teoría Tradicional y Teoría Crítica. Universitas Humanística, 49(49), 29-41, e-ISSN: 2011-2734. Recuperado de: https://revistas.javeriana.edu.co/index.php/univhumanistica/article/view $\underline{19560}$

Echeverría, B. (2010a,b,c). Imágenes de Blanquitud. En B. Echeverría, Modernidad y Blanquitud. México, D.F.: Ediciones Era.

Echeverría, B. (2001a,b,c). La dimensión cultural de la vida social. En B. Echeverría, Definición de la cultura. México, D.F.: Editorial Itaca.

Freud, S. (1992a,b). El malestar en la cultura. Argentina: Amorrortu Editores. Nietzsche, F. (1996a,b,c,d,e,f). La genealogía de la moral. Madrid, España: Alianza Editorial.

Quijano, A. (2000a,b,c,d). Colonialidad del poder, eurocentrismo y América

Latina. En E. Lander, La colonialidad del saber: eurocentrismo y ciencias sociales. Buenos Aires, Argentina: CLACSO.

Weber, M. (2012a,b). La ética protestante y el espíritu del capitalismo. México, D.F.: Editorial Fondo de Cultura Económica. 


\section{Mireya Yolanda Arias Palomeque \\ e-mail: mireya.arias@unae.edu.ec}

Nacida en Sucúa, Ecuador, el 12 de septiembre de 1989.

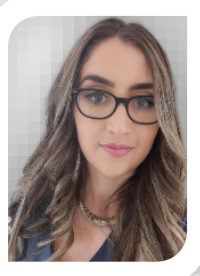

Docente Investigadora de la Universidad Nacional de Educación (UNAE); Magíster en Investigación en Sociología; Abogada de los tribunales de la República; Licenciada en Ciencias de la Comunicación Social; Principales intereses investigativos: educación, cultura, género, Educomunicación; Becaria de la Fundación Botín para el fortalecimiento de la Función Pública en Latinoamérica; Becaria de la Embajada de EE.UU. en el programa Jóvenes Embajadores del Ecuador. 